\title{
Risk Assessment of Deep Foundation Pit Construction Based on Analytic Hierarchy Process and Fuzzy Mathematics
}

\author{
Guowang Meng, ${ }^{1,2}$ Jingsong Huang $\mathbb{D}^{1},{ }^{1} \mathrm{Bo} W u\left(\mathbb{D},{ }^{1,2}\right.$ Yanping $\mathrm{Zhu},{ }^{3}$ Shixiang Xu, ${ }^{1,2}$ \\ and Jianhua $\mathrm{Hao}^{4}$ \\ ${ }^{1}$ College of Civil Engineering and Architecture, Guangxi University, Nanning, Guangxi 530004, China \\ ${ }^{2}$ Key Laboratory of Disaster Prevention and Structural Safety of Ministry of Education, Guangxi University, Nanning, \\ Guangxi 530004, China \\ ${ }^{3}$ Department of Civil, Architectural, and Environmental Engineering, Missouri University of Science and Technology, Rolla, \\ MO 65401, USA \\ ${ }^{4}$ The Second Engineering, Ltd. of CTCE Group, Suzhou, Jiangsu 215000, China
}

Correspondence should be addressed to Jingsong Huang; 164502262@qq.com and Bo Wu; wubo@gxu.edu.cn

Received 18 May 2020; Revised 17 October 2020; Accepted 21 October 2020; Published 4 November 2020

Academic Editor: Paul Awoyera

Copyright (c) 2020 Guowang Meng et al. This is an open access article distributed under the Creative Commons Attribution License, which permits unrestricted use, distribution, and reproduction in any medium, provided the original work is properly cited.

\begin{abstract}
The construction risk of deep foundation pit (DFP) engineering is high, and accidents occur frequently. It is necessary to evaluate the risk of deep foundation pits before construction. At present, although there are many risk assessment methods, there is not one with strong applicability and high accuracy. Based on expert scoring, this paper analyses the risk from two aspects (the severity of consequences and the probability of occurrence), divides the severity of the consequences into five indexes, calculates the risk by using the analytic hierarchy process (AHP), and sets the expert weight index so that the subjective expert scoring result can obtain the best possible objective calculation result. In addition, this paper uses the membership function from fuzzy mathematics to establish the level of risk and optimize the evaluation criteria of risk events. An engineering example is introduced, and the result of the risk assessment shows that the evaluation result $\mathrm{R}$ (risk value) obtained by the optimized risk assessment method in this paper is 7.9 and that the level of risk is grade III. The risk assessment method proposed in this paper has strong applicability and can obtain more accurate evaluation results. This method can provide a reference for the risk assessment of deep foundation pit engineering.
\end{abstract}

\section{Introduction}

Accidents occur frequently in DFP engineering, especially in subway DFP engineering. Once an accident occurs during the construction of a DFP, it will cause huge economic losses, casualties, and social panic. Meanwhile, with the rapid development of urban rail transit in many countries, such as the urban rail transit that networks Chinese roads [1], urban rail transit has become indispensable, leading to many safety problems in their construction processes [2]. According to the latest data statistics, most accidents occur during the construction process of DFPs for subway stations [3-5]. In order to reduce the construction risk and reduce the occurrence of various accidents effectively, it is necessary to identify and evaluate the construction risk before formal construction scientifically, accurately, and comprehensively.

In recent years, many risk assessment methods have been widely used, the risk assessment system is more perfect, the application of methods is more mature, there is more emphasis on the mixed application of multiple methods, and more attention has been given to the combination of subjective and objective methods. Chen et al. [6] comprehensively summarized the advantages and disadvantages of many risk assessment methods, including the analytic hierarchy process (AHP), the network analysis method (ANP), fuzzy comprehensive evaluation, the Bayesian network, the influence diagram method, the risk matrix method, the fault tree method, the FMEA method (failure probability), the 
simulation method, the Monte Carlo method, the artificial neural network (ANN), and other methods. Although there is no in-depth analysis of the theory, it is concluded that the risk assessment method used should be more focused on engineering applications to improve its operability and applicability. According to Yan et al. [7], the risk is uncertain, stochastic, relevant, and fuzzy in nature; therefore, they developed a fuzzy analysis network process (FANP). In this process, a fuzzy comprehensive evaluation is used to solve the uncertainty and fuzziness in expert judgements, the ANP is used to establish a causal relationship model between the same or different levels of risks, and a good evaluation effect is obtained. He et al. [8] used rough set theory and the disaster progression method to evaluate the construction risk of a subway station DFP and analyzed the influence of DFP accident interaction causes on accidents. By processing data and taking a subway station DFP construction as an example, a better evaluation result can be obtained. Valipouret al. [9] adopted the SWARA (Stepped Weight Assessment Ratio Analysis) and COPRAS (COmplex PRoportional ASsessment) methods to collect data through interviews, a literature review, and a questionnaire survey given to excavation engineering experts. Taking a DFP project in Iran as an example, the results show that construction safety risk, unfavourable geological conditions, a lack of management experience, imperfect emergency plans, and land subsidence are the main risks of excavation engineering in the Shiraz area. This method is essentially an expert survey method, but the evaluation criteria are different. It can be seen that many DFP engineering risk assessments tend to use the relatively simple and direct expert survey method as the main risk assessment method. Islam et al. [10] compiled and analyzed the basic concepts and methods of fuzzy theory applied in the field of construction project risk assessment from 2005 to 2017. It can be seen from the paper that fuzzy theory is widely used in risk assessment and has evolved into a mixed method using many different methods, which include the fuzzy probability method, fuzzy matrix method, fuzzy structure method, and so on. Different types of fuzzy cloud models and fuzzy integral processes are described in detail in this paper and are worth studying. Giannakos and Xenidiset al. [11] used historical data to study the complexity of the relationship between the overall risk and the individual risk by using the artificial neural network method. The results show that the overall risk is no longer a simple superposition of individual risks, and it involves the complex relationship of interdependence. This is a problem worthy of thought and deep research. Currently, machine learning is the most promising method for risk assessment, and related research has been published in the top risk management journal, Accident analysis and prevention. Among the articles on machine learning, artificial neural networks (ANNs) are the most popular machine learning algorithms, and support vector machines (SVMs) are the second most popular. More than $70 \%$ of the articles use historical data sets, and more than $20 \%$ use real-time data to build machine learning models. Approximately half of the methods adopt the case study method to realize the machine learning model, and approximately a quarter of the methods have been implemented in reality [12] (2020).

However, among these risk assessment methods, the most direct and effective method to conduct an evaluation is directly using the rich engineering experience of experts $[13,14]$, but the issue of how to use and select experts' suggestions must be considered reasonably and accurately.

This paper optimizes the risk assessment method on the basis of expert scoring and optimizes it from the following three aspects. First, according to the GB-50652-2011 Code for risk management of underground works in urban rail transit, the index of consequence severity is analyzed in detail. This index is divided into five indexes (casualties, economic losses, construction delays, environmental impacts, and social impacts), and the corresponding weights are calculated by the AHP. Second, by assessing a large amount of engineering practice data, in this paper, the five indexes used to determine the weight of experts are summed up, and the expert weight is added to solve the total risk value. Third, the membership function from fuzzy mathematics and the confidence degree of sample estimation in mathematical statistics are introduced to optimize the judgement standard of the risk level so as to make the evaluation result more scientific and credible.

\section{Theoretical Bases}

2.1. AHP. AHP is a qualitative and quantitative combination of systematic, hierarchical analysis methods. The characteristic of this method is that when applied to an in-depth study on nature, influencing factors, and internal relations of complex decision-making problems, it uses less quantitative information to make the decision-making process mathematical, thus providing a simple decision-making method for complex decision-making problems with multiple objectives, multiple criteria, or no structural characteristics. It is a model and method to make decisions for complex systems that are difficult to fully quantify.

The principle of the AHP is that according to the nature of the problem and the overall goal to be achieved, the problem can be decomposed into different constituent factors, and the factors are aggregated and combined at different levels according to the relationship between the factors and the subordinate relationship, forming a multilevel analysis structure model. The problem is finally reduced to the lowest level (for decision-making programs, measures, etc.) relative to the highest level, the determination of the relative importance weights of layers (general objective), or the arrangement of a relatively superior and inferior order.

In this paper, the AHP is used to obtain the relative importance weight of a risk event relative to the total risk of DFP engineering and the relative importance weights of five risk loss indexes. The calculation process of the AHP is quite common, and thus it will not be discussed in this paper.

2.2. Indicators of Expert Weights. Using a large amount of literature data, the method for determining expert weights is summarized for DFP projects. As shown in Table 1, the five 
TABLE 1: Expert evaluation index table.

\begin{tabular}{|c|c|c|c|c|c|}
\hline Index $(Z)$ & & & Index grade & & \\
\hline Years of relevant work $(Z 1)$ & $0-5$ years & 5-10 years & $10-15$ years & $15-20$ years & over 20 years \\
\hline Educational grade $(Z 2)$ & Specialist & Undergraduate & Postgraduate & PhD student & postdoc \\
\hline Degree $(Z 3)$ & Other & College & Bachelor's & Master's degree & $\mathrm{PhD}$ \\
\hline Professional and technical titles $(Z 4)$ & Other & Junior & Intermediate & Deputy senior & senior \\
\hline Received the highest prize $(Z 5)$ & Other & City grade & Provincial grade & National grade & world-class \\
\hline Rank assignment & 1 & 2 & 3 & 4 & 5 \\
\hline
\end{tabular}

evaluation indexes can be seen, and each index has five grades. The five indexes of each expert are scored, and the total score of each expert is normalized to obtain the weight value of each expert.

2.3. Consequence Severity Grades. According to GB-506522011 [15], the consequence severity includes casualties (construction personnel), economic losses (the project itself), construction delays (long-term engineering), environmental impacts, and social impacts. These five indexes are used to judge the final consequence of severity results. The consequence severity indexes are shown in Table 2.

A judgement matrix is constructed for the five indexes. According to the AHP, the corresponding weights of the five indexes can be obtained. Corresponding to these five indexes, the consequence severity grade is divided into five grades. The grade standards are shown in Table 3.

2.4. Occurrence Likelihood Grades. According to the risk occurrence probability, the probability of engineering risk can be divided into five grades using the frequency or probability as an indicator. The grade standards are shown in Table 4.

2.5. Scoring Rules. Based on the risk grading standards in the GB-50652-2011, the risk value $R$ can be calculated quantitatively. The scoring standards for the risk event are specified as follows:

The occurrence likelihood grade $P: 1,2,3,4$, and 5; the corresponding scores: $5,4,3,2$, and 1 .

The consequence severity grade $C: A, B, C, D$, and $E$; the corresponding scores: $5,4,3,2$, and 1 . [16]:

The risk value $R$ is calculated by the following formula

$$
R=P \times C .
$$

2.6. Risk Classification Criteria. The risk classification criteria are elaborated based on risk value grades, as shown in Table 5 .

It can be seen from Table 5 that the risk values are divided into four risk grades: I $[15,25)$, II $[10,15)$, III $[4,10)$, and IV $[1,4)$. However, the expert risk assessment process is often fuzzy, and the boundary between different risk grades is also fuzzy. For example, $R=10$ is defined as grade II by Table 5 , but in fact, $R=10$ may also be grade III. Therefore, the membership function $\mu(x)$ must be introduced to determine the degrees of membership of $R=10$ to grade II and grade III, and then the principle of the maximum degree of membership is used to judge and choose the most suitable grade.

In fuzzy mathematics, first, it is necessary to confirm the membership function of the research object. In the paper engineering fuzzy mathematics and its application [17], the most commonly used distribution for the membership function of the risk grade is the normal distribution expressed as follows:

$$
\mu(x)=e^{-((x-a) / b)^{2}} .
$$

The distribution curve is shown in Figure 1.

The fuzzy set theory represents an efficient way to deal with fuzziness resulting from informal and lexical uncertainty [18]. Because the degree of fuzziness of a risk value is the largest when it is at the boundary between two risk grades, it can be assumed that the risk grade falls into the universe of discourse $U=\{x \mid 1 \leq x \leq 25\}$, where $\underline{A}=$ grade I $\left(x_{1}\right)$, grade II $\left(x_{2}\right)$, grade III $\left(x_{3}\right)$, and grade IV $\left.\left(x_{4}\right)\right\}$ are its fuzzy subset and $x$ is the risk value $R$. On the boundary between two risk grades, the degree of membership of the two risk grades $\mu_{A}(x)=0.5$ and the degree of fuzziness $d(\underline{A})=1$ are at their maximum. The closer the membership function of a fuzzy set is to 0.5 , the fuzzier it is. The commonly used triangular fuzzy numbers and trapezoidal fuzzy numbers cannot accurately express the relationship between risk grades [19]. Regardless, the clearer the membership is, the farther away the value is from 0.5 . It should be highlighted that the membership function selected in this paper is a normal distribution, referring to the degree of confidence and confidence interval of the sample estimation of mathematical statistics. Considering the membership function as a probability sample, the confidence $a$ is equal to 0.5 ; the confidence interval is the risk grade interval; $a$ is the expected value of the sample (i.e., the centre value of the risk grade interval); and $b$ is the standard deviation of the sample, which can be obtained through the calculation of the degree of confidence and the confidence interval. The membership function of each risk grade can be calculated as follows:

Grade I membership function:

$$
\mu_{\underline{A}}\left(x_{1}\right)= \begin{cases}e^{-\left(\left(x_{1}-20\right) / 7.4\right)^{2}}, & 1 \leq x_{1}<20, \\ 1, & 20 \leq x_{1} \leq 25 .\end{cases}
$$


TABLe 2: Indexes of the consequence severity.

\begin{tabular}{|c|c|c|c|c|c|}
\hline Assignment & $\begin{array}{l}\text { Severe injury }(F) \text { death }(\mathrm{SI}) / \\
\text { person }\end{array}$ & $\begin{array}{c}\text { Economic losses } / 10,000 \\
\text { RMB }\end{array}$ & $\begin{array}{c}\text { Construction delays/ } \\
\text { months }\end{array}$ & $\begin{array}{l}\text { Environmental } \\
\text { impacts }\end{array}$ & Social impacts \\
\hline 5 & SI $>10$ & $>1000$ & $>9$ & Very large & Terrible \\
\hline 4 & $9 \geq \mathrm{SI} \geq 3$ or $F \geq 10$ & $(1000,500]$ & $(9,6]$ & Big & Serious \\
\hline 3 & $2 \geq \mathrm{SI} \geq 1$ or $9 \geq F \geq 2$ & $(500,100]$ & $(6,3]$ & Big & More serious \\
\hline 2 & $\begin{array}{c}F=1 \text { or } 10 \geq \text { minor } \\
\text { injuries } \geq 2\end{array}$ & $(100,50]$ & $(3,1]$ & Smaller & $\begin{array}{l}\text { Need to } \\
\text { consider }\end{array}$ \\
\hline 1 & Minor injuries $=1$ & $<50$ & $<1$ & Very small & Ignorable \\
\hline
\end{tabular}

TABLE 3: The consequence severity grades.

\begin{tabular}{lccccc}
\hline Grade & A & B & C & D & E \\
\hline Severity & Disastrous & Very serious & Serious & Things to consider & Ignorable \\
Assignment $(\mathrm{C})$ & 5 & 4 & 3 & 1 \\
\hline
\end{tabular}

TABLE 4: The occurrence likelihood grades.

\begin{tabular}{lcccc}
\hline Grade & 5 & 4 & 3 & 2 \\
\hline Accident description & Impossible & Rarely happens & Happens occasionally & May happen \\
Probability interval & $P<0.01 \%$ & $0.01 \% \leq P<0.1 \%$ & $0.1 \% \leq P<1 \%$ & $1 \% \leq P<10 \%$ \\
Assignment (P) & 1 & 2 & 3 & $P \geq 10 \%$ \\
\hline
\end{tabular}

TABLe 5: Risk classification criteria.

\begin{tabular}{lccc}
\hline Grade & Risk value $R$ & Acceptance criteria & Disposal principle \\
\hline Grade I & $15 \leq R$ & Unacceptable & Preventive measures to reduce risks must be implemented at all costs \\
Grade II & $10 \leq R$ & Unwilling to accept & Identify and implement precautions to reduce risk \\
Grade III & $4 \leq R$ & Acceptable & Risks are tolerable and precautions may be needed \\
Grade IV & $1 \leq R$ & Ignorable & Risks are tolerable and no additional measures are required \\
\hline
\end{tabular}

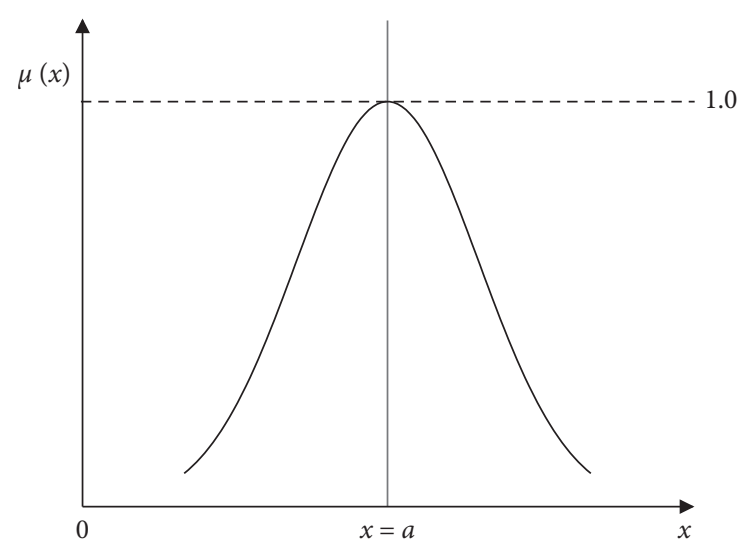

FIgURE 1: Normal distribution membership function.

Grade II membership function:

$$
\mu_{\underline{A}}\left(x_{2}\right)=e^{-\left(\left(x_{2}-12.5\right) / 3.9\right)^{2}}, \quad 1 \leq x_{2} \leq 25 .
$$

Grade III membership function:

$$
\mu_{\underline{A}}\left(x_{3}\right)=e^{-\left(\left(x_{3}-7\right) / 4.4\right)^{2}}, \quad 1 \leq x_{3} \leq 25 .
$$

Grade IV membership function:

$$
\mu_{\underline{A}}\left(x_{4}\right)= \begin{cases}1, & 1 \leq x_{4}<2.5 \\ e^{-\left(\left(x_{4}-2.5\right) / 2.2\right)^{2}}, & 2.5 \leq x_{4} \leq 25 .\end{cases}
$$

The curve distributions of the above four membership functions are shown in Figure 2.

The risk value $R$ of each risk event is input into formulas (3)-(6) to calculate the corresponding degree of membership and to determine the risk grade of each risk event according to the principle of the maximum degree of membership in fuzzy mathematics by comparing calculation results.

\section{Risk Assessment Process}

The risk assessment process [20, 21] is shown in Figure 3. The list of risks is compiled using the WBS-RBS method based on the relevant information of the DFP project $[22,23]$. Then, experts score the five indexes of the occurrence probability and loss of the risk event. Compared with only scoring the risk probability and loss, we can obtain more abundant evaluation content and make a more refined assessment. The obtained scores of the indexes are used to determine the weights of each expert, and the main purpose 


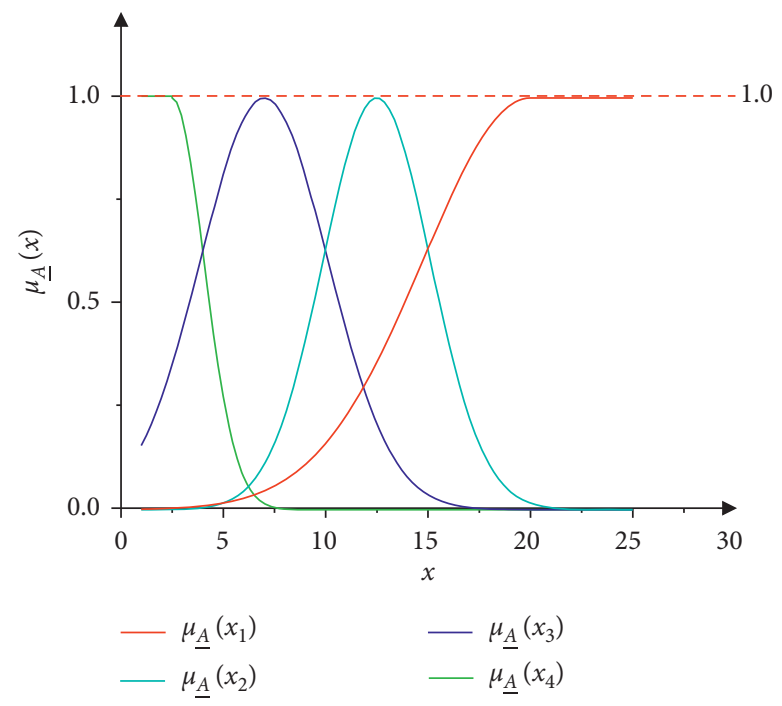

FIGURE 2: Curve distributions of risk grade membership functions.

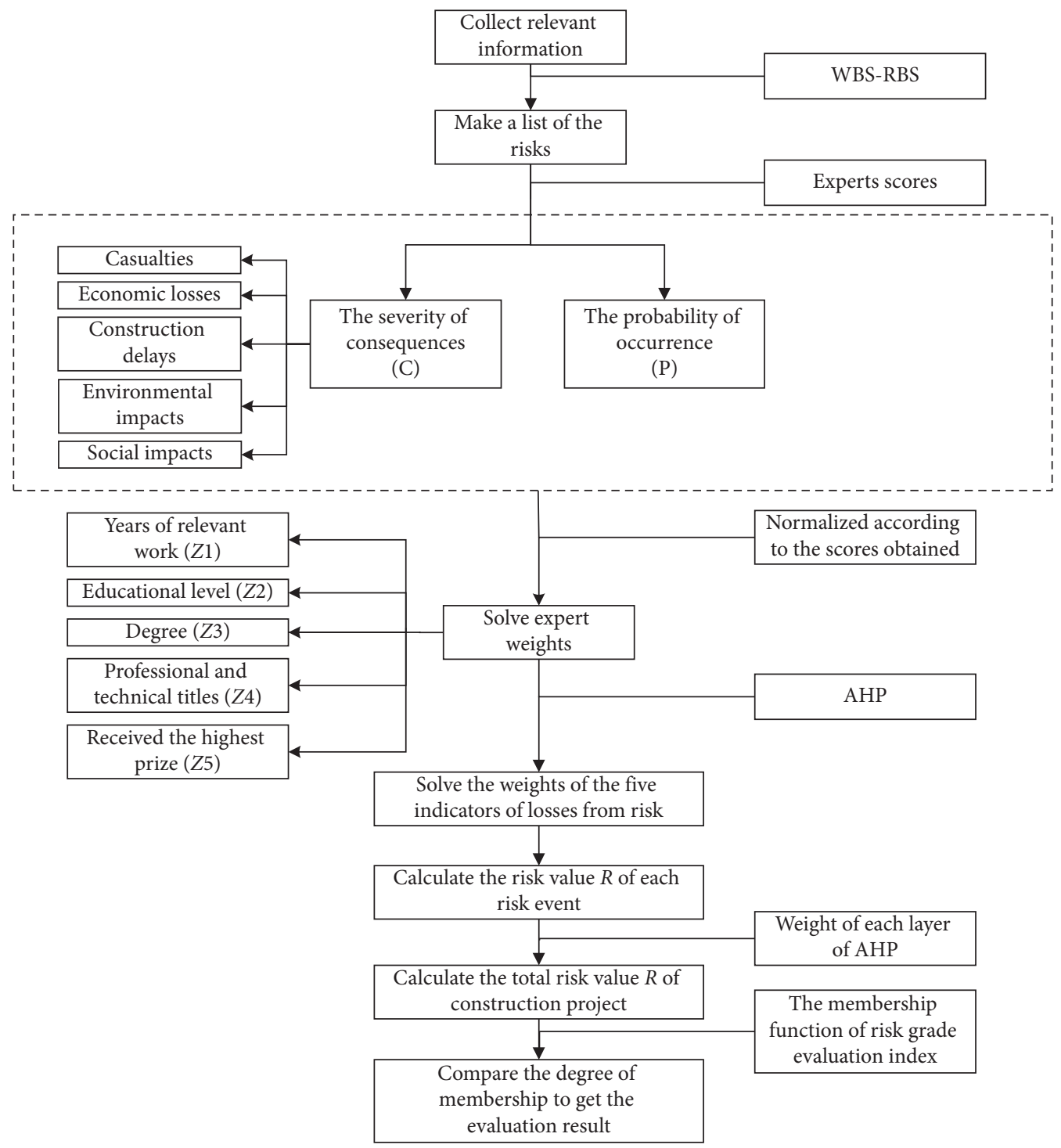

Figure 3: Calculation flowchart. 


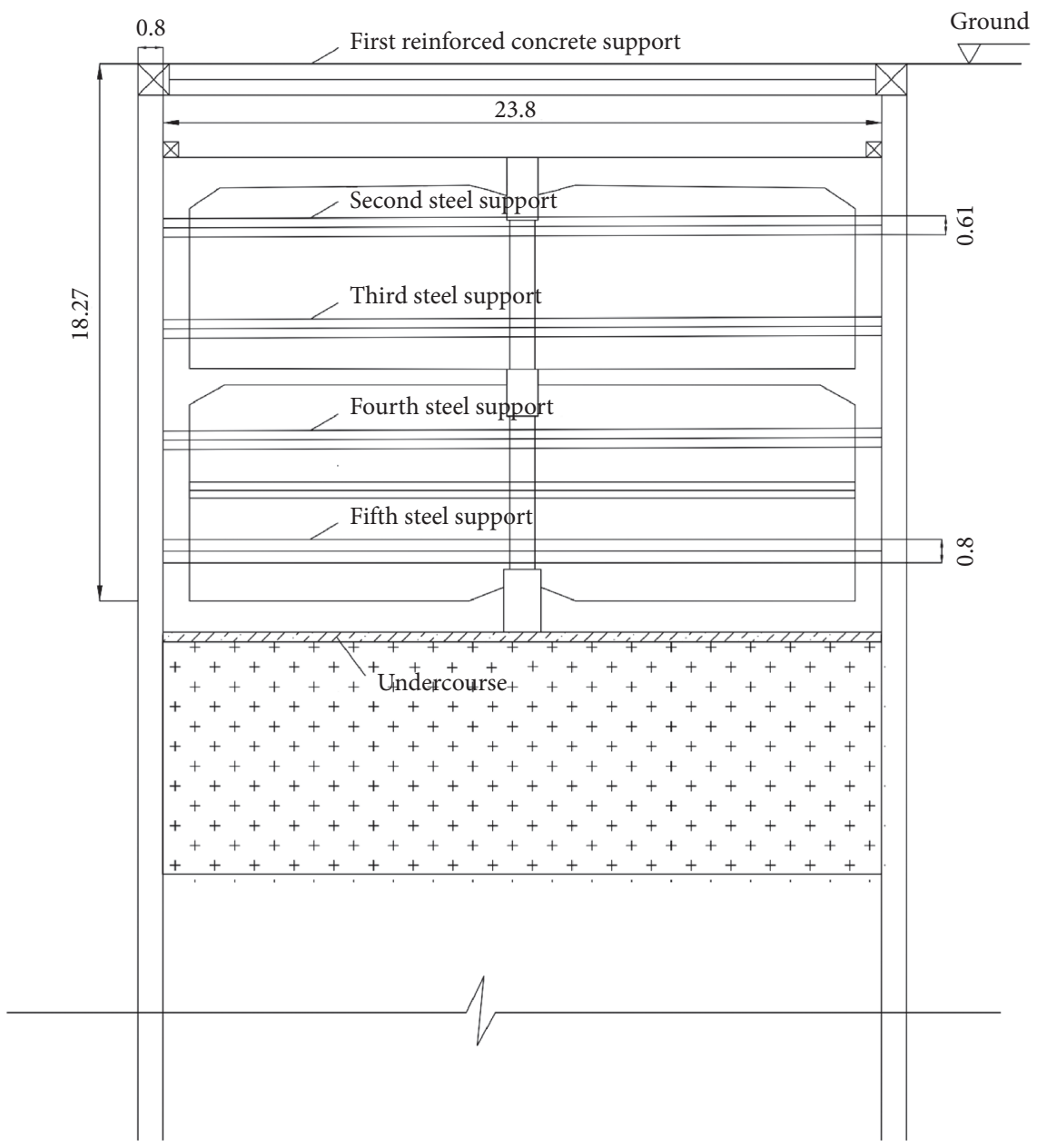

Figure 4: Cross section of the foundation pit.

of setting expert weights is to reduce the adverse impacts of some experts' unprofessional evaluations on the evaluation results. The weights of the five indexes for the loss of risk events are calculated using the AHP, and the risk value of each risk event is calculated according to the risk value calculation formula. Finally, the total risk value of a DFP is calculated using the weight value of each subitem determined by the construction matrix of each layer. The membership function of the four risk grades is used to solve the corresponding degree of membership, and the degree of membership is compared to determine the risk grades of risk events. We use the membership function to determine the risk level because we hope to find a better way to evaluate the size of the risk rather than directly dividing the risk into four grades with clear boundaries.

We use the above three optimization measures to improve the risk assessment and to obtain the best possible risk assessment evaluation results. This method can be applied to engineering practice.

\section{Case Study}

4.1. Project Overview. Ningbo is a city in China. Songjiang East Road Station is a station of Ningbo Rail Transit. The underground standard section uses a two-story, singlecolumn, two-span (double-column three-span locally) cast in situ reinforced concrete frame structure. The length is approximately $169.60 \mathrm{~m}$, and the thickness of the topsoil at the centre of the station is approximately $2.99 \mathrm{~m}$. The width of the standard section foundation pit is $23.80 \mathrm{~m}$, and the depth of the standard section foundation pit is approximately $18.271 \sim 18.571 \mathrm{~m}$. The supporting structures for the main foundation pit of this station use an $800 \mathrm{~mm}$ diaphragm wall plus the internal supporting form. The sectional view of the station is shown in Figure 4. The depth of the water level outside the pit is related to the thickness of the fill layer. The engineering risks are divided into four categories: construction risk, environmental risk, natural risk, and geological risk. The optimized risk assessment method mentioned in Section 3 is adopted to evaluate the risk of the DFP during its construction.

4.2. Risk List. According to the actual project, the risk list is compiled using the WBS-RBS method. When establishing the risk list, we can refer to the contents of 4M1E (man, machine, method, material, and environment). After the risk event database is established using the WBS-RBS method, the risks are divided into four types: construction risk, 
TABle 6: Risk list.

\begin{tabular}{|c|c|c|c|c|}
\hline Risk type & Branch engineering & Risk unit & No. & Risk event \\
\hline \multirow{35}{*}{$\begin{array}{l}\text { Construction } \\
\text { risk }\end{array}$} & \multirow{7}{*}{ Main envelope structure } & \multirow{4}{*}{ Diaphragm wall } & 1 & Ground-to-wall invasion \\
\hline & & & 2 & Equipment overturn \\
\hline & & & 3 & Insufficient verticality \\
\hline & & & 4 & Bulge \\
\hline & & & 5 & Equipment overturn \\
\hline & & Drilling piles & 6 & Enclosing line \\
\hline & & & 7 & Broken pile \\
\hline & \multirow{5}{*}{$\begin{array}{c}\text { Foundation strengthening } \\
\text { works }\end{array}$} & \multirow{3}{*}{$\begin{array}{l}\text { High-pressure rotary } \\
\text { jet pile }\end{array}$} & 8 & Ground deformation caused by reinforcement \\
\hline & & & 9 & The curtain is not closed \\
\hline & & & 10 & Encounter obstacles \\
\hline & & \multirow{3}{*}{ Triaxial mixing pile } & 11 & Ground deformation caused by reinforcement \\
\hline & & & 12 & Encounter obstacles \\
\hline & \multirow{3}{*}{ Precipitation engineering } & & 13 & Water grade does not meet $1 \mathrm{~m}$ below the excavation surface \\
\hline & & \multirow{2}{*}{$\begin{array}{l}\text { Foundation pit } \\
\text { precipitation }\end{array}$} & 14 & Causes excessive deformation of the surrounding surface \\
\hline & & & 15 & $\begin{array}{l}\text { A water source channel is formed inside and outside the pit, } \\
\text { unable to precipitate }\end{array}$ \\
\hline & \multirow{14}{*}{ Earth excavation } & \multirow{7}{*}{ Support frame removal } & 16 & The support end face does not fit the continuous wall \\
\hline & & & 17 & Support active head is too long \\
\hline & & & 18 & Steel rafters are not tightly installed \\
\hline & & & 19 & Prestress is not applied in a timely manner \\
\hline & & & 20 & Too much or too little prestress is applied \\
\hline & & & 21 & Prestress loss is not added in time \\
\hline & & & 22 & Insufficient steel support reserves \\
\hline & & \multirow{7}{*}{ Excavation } & 23 & Excessive displacement of envelope structure \\
\hline & & & 24 & Pit bottom uplift \\
\hline & & & 25 & Unsupported exposure time is too long \\
\hline & & & 26 & Excavator crash support or support fall \\
\hline & & & 27 & $\begin{array}{c}\text { Excavation in layers and blocks without time-space effect, } \\
\text { insufficient sloping }\end{array}$ \\
\hline & & & 28 & Timely construction of cushion and floor \\
\hline & & & 29 & Longitudinal soil instability \\
\hline & \multirow{6}{*}{ Structural engineering } & \multirow{6}{*}{ Construction } & 30 & Waterproof layer failure \\
\hline & & & 31 & Irregular scaffolding \\
\hline & & & 32 & Scaffolding centralized loading \\
\hline & & & 33 & Insufficient formwork reinforcement \\
\hline & & & 34 & Concrete pouring discontinuity \\
\hline & & & 35 & Concrete curing is not timely \\
\hline
\end{tabular}

natural risk, geological risk, and environmental risk. It is equivalent to using the checklist method to identify the risks and screen out the risks existing in the construction. The final result is the formation of the project risk list. The list is shown in Table 6.

4.3. Expert Scoring. This risk assessment invited 10 relevant experts in the industry to participate. The relevant background information about the project was given to each expert, including design drawings, geological survey data, and construction organization design. After careful review, the experts scored each risk event listed. The five indexes of the consequence severity and the occurrence likelihood are scored separately, and the corresponding grade points are assigned. In the expert scoring process, the risk radar chart is used to optimize the scoring interface to make the scoring of risk events more intuitive and simpler. As shown in Figure 5, the risk assessment indicators of each risk event are expanded into a risk radar chart, and each risk event is summarized into a scoring table. The scoring tables of each expert are finally summarized using the AHP, which is used for the next calculation of the total risk value. The final scoring table for expert 1 is shown in Table 7.

4.4. Consequence Severity Index Weights. Each expert fills in the corresponding values based on a pair of judgement matrices composed of casualties, economic losses, construction delays, environmental impacts, and social impacts. The AHP is applied for the weight calculation and consistency test. The relative weights of the five indexes of the consequence severity are obtained as $w_{i}(i=1,2, \ldots, 10)$. The $w_{1}$ is evaluated by expert 1 are shown in Table 8 .

Figure 6 is the score chart (expert 1) with the five indexes of the consequence severity for each risk event. The risk loss value is obtained by multiplying the five index scores and the corresponding weight values. As a result, the red line indicates the result after considering the weights of the five indexes, and the blue line is the average of the five indexes. We can clearly see that there are obvious differences between the two lines. If we do not decompose the consequence 


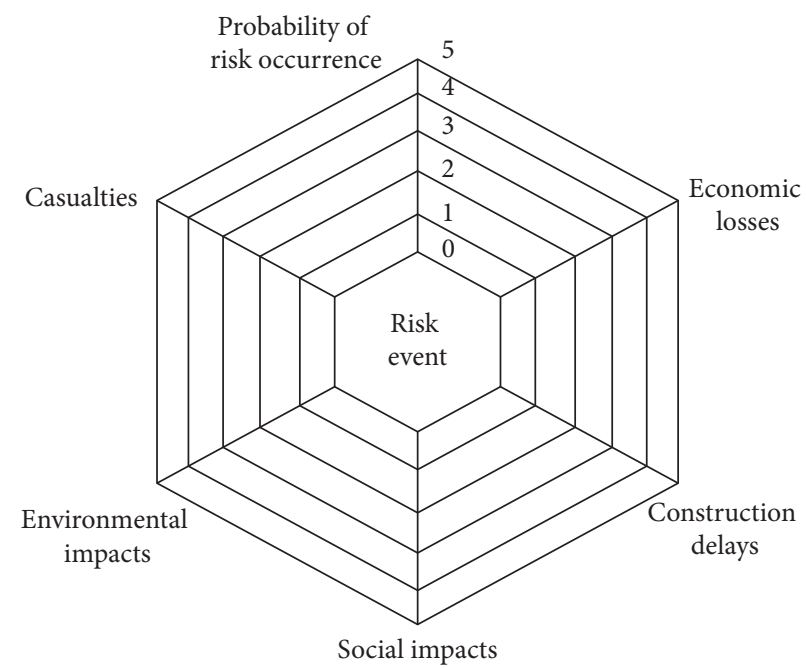

FIgURE 5: Radar chart of the risk event evaluation index.

TABle 7: Expert 1 score sheet.

\begin{tabular}{|c|c|c|c|c|c|c|c|}
\hline Risk event (no.) & $\begin{array}{l}\text { Occurrence } \\
\text { likelihood }\end{array}$ & $\begin{array}{c}\text { Economic } \\
\text { losses }\end{array}$ & Casualties & $\begin{array}{c}\text { Construction } \\
\text { delays }\end{array}$ & $\begin{array}{c}\text { Environmental } \\
\text { impacts }\end{array}$ & $\begin{array}{c}\text { Social } \\
\text { impacts }\end{array}$ & $\begin{array}{l}\text { Risk } \\
\text { value }\end{array}$ \\
\hline Ground wall invasion limit (1) & 3 & 4 & 3 & 2 & 3 & 3 & 10.2 \\
\hline Equipment overturn (2) & 1 & 4 & 1 & 3 & 3 & 5 & 3.5 \\
\hline Insufficient verticality (3) & 2 & 4 & 5 & 4 & 4 & 5 & 8.5 \\
\hline Bulge (4) & 2 & 1 & 1 & 1 & 2 & 3 & 2.7 \\
\hline Equipment overturn (5) & 3 & 4 & 5 & 3 & 2 & 4 & 11.4 \\
\hline Limit of enclosing pile (6) & 2 & 4 & 4 & 4 & 5 & 1 & 7.5 \\
\hline Broken pile $(7)$ & 5 & 1 & 5 & 2 & 1 & 1 & 8.2 \\
\hline $\begin{array}{l}\text { Ground deformation caused by } \\
\text { reinforcement (8) }\end{array}$ & 1 & 4 & 4 & 4 & 1 & 1 & 3.3 \\
\hline The curtain is not closed (9) & 4 & 4 & 2 & 2 & 4 & 1 & 12.7 \\
\hline Encounter obstacles (10) & 1 & 2 & 2 & 1 & 4 & 1 & 2.0 \\
\hline $\begin{array}{l}\text { Ground deformation caused by } \\
\text { reinforcement (11) }\end{array}$ & 1 & 3 & 3 & 4 & 2 & 4 & 3.1 \\
\hline Encounter obstacles (12) & 1 & 4 & 4 & 4 & 5 & 4 & 4.1 \\
\hline $\begin{array}{l}\text { Water grade does not meet } 1 \mathrm{~m} \\
\text { below the excavation surface }(13)\end{array}$ & 2 & 1 & 1 & 2 & 2 & 2 & 2.7 \\
\hline $\begin{array}{l}\text { Causes excessive deformation of the } \\
\text { surrounding surface (14) }\end{array}$ & 5 & 1 & 3 & 3 & 3 & 2 & 9.2 \\
\hline $\begin{array}{l}\text { A water source channel is formed } \\
\text { inside and outside the pit, unable to } \\
\text { precipitate (15) }\end{array}$ & 5 & 1 & 2 & 4 & 1 & 3 & 8.6 \\
\hline $\begin{array}{l}\text { The support end face does not fit the } \\
\text { continuous wall (16) }\end{array}$ & 3 & 3 & 2 & 2 & 2 & 1 & 7.2 \\
\hline Support active head is too long (17) & 5 & 3 & 3 & 5 & 1 & 1 & 13.9 \\
\hline $\begin{array}{l}\text { Steel rafters are not tightly installed } \\
\text { (18) }\end{array}$ & 1 & 3 & 4 & 5 & 3 & 4 & 3.5 \\
\hline $\begin{array}{l}\text { Prestress is not applied in a timely } \\
\text { manner (19) }\end{array}$ & 1 & 1 & 1 & 4 & 2 & 1 & 1.5 \\
\hline $\begin{array}{l}\text { Too much or too little prestress is } \\
\text { applied (20) }\end{array}$ & 4 & 3 & 5 & 2 & 3 & 1 & 11.7 \\
\hline $\begin{array}{l}\text { Prestress loss is not added in time } \\
\text { (21) }\end{array}$ & 4 & 3 & 4 & 2 & 1 & 3 & 11.1 \\
\hline $\begin{array}{l}\text { Insufficient steel support reserves } \\
(22)\end{array}$ & 1 & 1 & 3 & 1 & 2 & 2 & 1.5 \\
\hline $\begin{array}{l}\text { Excessive displacement of the } \\
\text { envelope structure (23) }\end{array}$ & 3 & 1 & 5 & 3 & 2 & 4 & 6.6 \\
\hline Pit bottom uplift (24) & 2 & 5 & 1 & 4 & 3 & 1 & 7.4 \\
\hline
\end{tabular}


TABLE 7: Continued.

\begin{tabular}{|c|c|c|c|c|c|c|c|}
\hline Risk event (no.) & $\begin{array}{l}\text { Occurrence } \\
\text { likelihood }\end{array}$ & $\begin{array}{l}\text { Economic } \\
\text { losses }\end{array}$ & Casualties & $\begin{array}{c}\text { Construction } \\
\text { delays }\end{array}$ & $\begin{array}{l}\text { Environmental } \\
\text { impacts }\end{array}$ & $\begin{array}{c}\text { Social } \\
\text { impacts }\end{array}$ & $\begin{array}{l}\text { Risk } \\
\text { value }\end{array}$ \\
\hline $\begin{array}{l}\text { Unsupported exposure time is too } \\
\text { long (25) }\end{array}$ & 3 & 5 & 5 & 2 & 1 & 3 & 11.9 \\
\hline $\begin{array}{l}\text { Excavator crash support or support } \\
\text { fall (26) }\end{array}$ & 1 & 3 & 2 & 3 & 4 & 1 & 2.8 \\
\hline $\begin{array}{l}\text { Excavation in layers and blocks } \\
\text { without time-space effect, } \\
\text { insufficient sloping ( } 27)\end{array}$ & 5 & 1 & 4 & 1 & 5 & 3 & 10.4 \\
\hline $\begin{array}{l}\text { Timely construction of cushion and } \\
\text { floor }(28)\end{array}$ & 1 & 5 & 4 & 3 & 4 & 1 & 4.1 \\
\hline Longitudinal soil instability (29) & 2 & 5 & 3 & 2 & 5 & 4 & 8.6 \\
\hline Waterproof layer failure (30) & 1 & 4 & 2 & 2 & 2 & 4 & 3.3 \\
\hline Irregular scaffolding (31) & 5 & 5 & 3 & 1 & 4 & 1 & 18.5 \\
\hline Scaffolding centralized loading (32) & 3 & 2 & 2 & 1 & 4 & 1 & 6.0 \\
\hline $\begin{array}{l}\text { Insufficient formwork reinforcement } \\
\text { (33) }\end{array}$ & 5 & 2 & 3 & 5 & 1 & 1 & 11.2 \\
\hline Concrete pouring discontinuity (34) & 3 & 1 & 3 & 2 & 4 & 2 & 5.5 \\
\hline Concrete curing is not timely (35) & 4 & 2 & 2 & 1 & 3 & 3 & 8.5 \\
\hline
\end{tabular}

TABle 8: The weights of the five indicators of the consequence severity (expert 1).

\begin{tabular}{lccccc}
\hline Index & Economic losses & Casualties & Construction delays & Environmental impacts & Social impacts \\
\hline Weight & 0.524 & 0.129 & 0.116 & 0.116 & 0.116 \\
\hline
\end{tabular}

severity into five indexes, the result is obviously not comprehensive enough for the actual project. If we only consider one of the indexes, such as if we only consider the economic losses index, we cannot correctly evaluate the risk value. After considering the five indexes, the difference between risk values can reach approximately $30 \%$ in some risk events. If the consequence severity cannot be accurately evaluated, the calculation result of the risk value will also be affected. In practical engineering, accurate risk assessment is essential and very important. Obviously, the red line considering the weights of the five indexes of the consequence severity is more reasonable and scientific.

4.5. Expert Weights. In the risk assessment, the most effective and convenient method is to use the experts' rich personal construction experience to conduct the quantitative grading evaluation of the construction risk. However, due to the different field experiences and professional levels of each expert, there may be large deviations in the assessments of the same risk event, which will affect the final assessment result. Therefore, it is necessary to allocate the weight of each assessment expert. After each expert fills in the information of the designated content, the score of each expert is calculated according to the grading score, and then the weights of each expert are used to normalize the score. The weights $w_{0}$ of each expert are shown in Table 9.

The expert fills in the judgement matrix of the risk unit of each subitem, and the weight of each risk event can be calculated using the AHP. Taking the data filled in by expert 1 as an example, the weight $w$ of expert 1 to each risk unit can be obtained as follows: diaphragm wall $(0.032,0.021,0.037$, and 0.031), drilling piles (0.020, 0.033, and 0.037), highpressure rotary jet grouting pile $(0.036,0.032$, and 0.037$)$, triaxial mixing pile $(0.024$ and 0.038$)$, foundation pit precipitation $(0.027,0.030$, and 0.028$)$, support frame removal $(0.030,0.022,0.024,0.035,0.025,0.032$, and 0.038$)$, excavation $(0.028,0.022,0.022,0.030,0.025,0.023$, and 0.022$)$, and construction $(0.026,0.027,0.032,0.034,0.020$, and 0.022).

The total risk value is calculated as follows:

$$
R=\sum_{i=1}^{n} w_{i} R_{i}, \quad(i=1, \ldots, n)
$$

According to formula (7), the total risk value of expert 1 is $R=7.0$. In the same way, the evaluation results of the other experts for the final total risk value are shown in Table 10.

The results in Figure 7 show that the final score of each expert is different, the gap between the highest and the lowest is 2.1 , and the range of the scores is also relatively scattered. The figure also shows that each expert has different opinions on the project. Which expert should we believe in the evaluation result? Which expert's assessment is the most credible? After adding the weights of each expert, the total risk value finally calculated is $R=7.9$. In other words, the total risk value of project construction is 7.9. If the expert weights are not added, the average value of each expert evaluation result is 7.8 . Therefore, we can draw the following conclusion: when several experts participate in the risk assessment, we should consider the weight of each expert. Although the difference between the scores of 7.8 and 7.9 is not obvious, the evaluation result after considering the weights of experts is more reasonable and credible. 


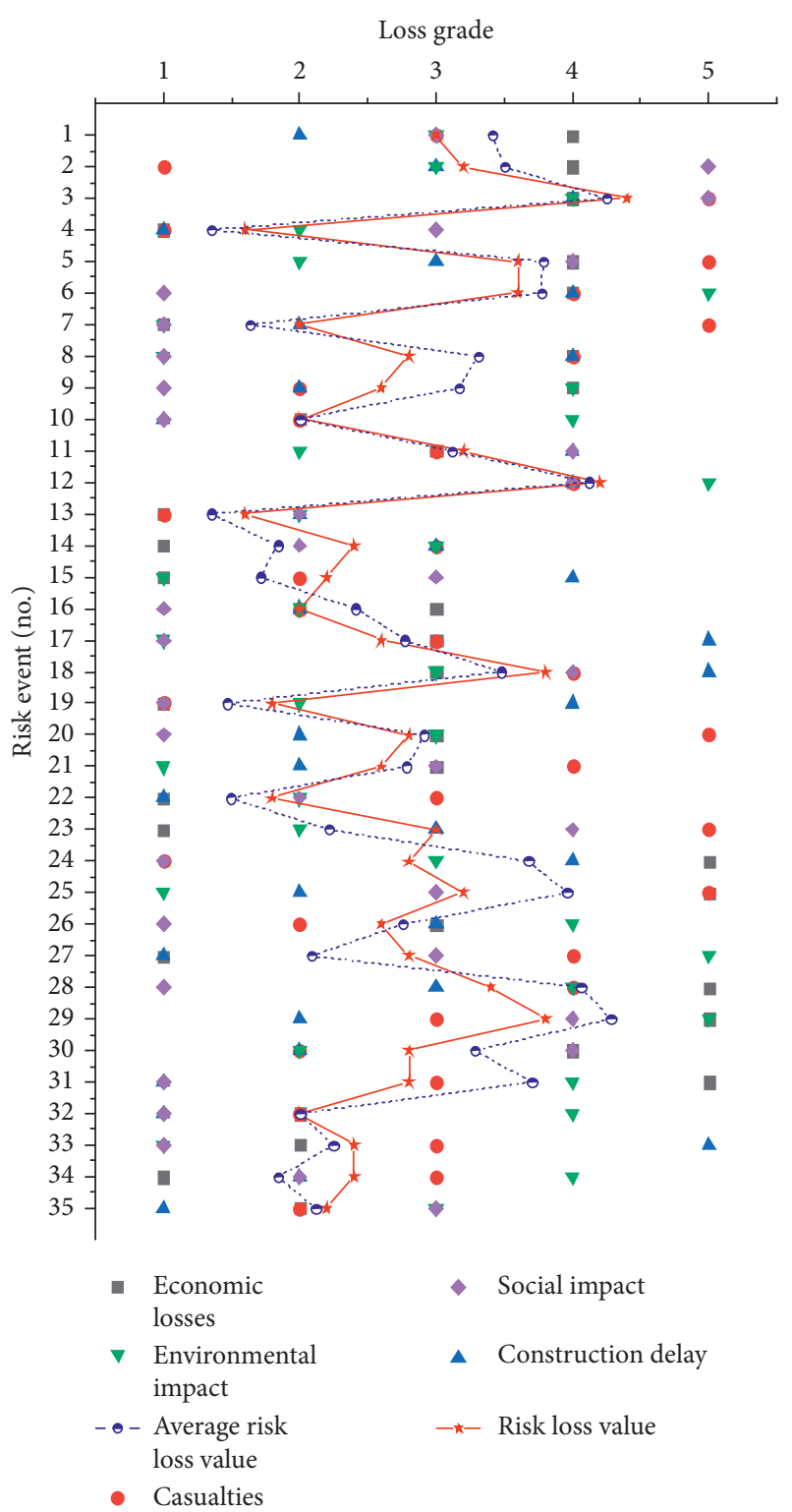

Figure 6: Scores of the loss indicators for each risk event.

TABLE 9: Expert indicator score.

\begin{tabular}{lccccccc}
\hline Expert & $Z 1$ & $Z 2$ & $Z 3$ & $Z 4$ & $Z 5$ & Score & Weight $w_{0}$ \\
\hline Expert 1 & 4 & 3 & 3 & 4 & 3 & 17 & 0.087 \\
Expert 2 & 4 & 5 & 5 & 4 & 2 & 20 & 0.103 \\
Expert 3 & 4 & 4 & 4 & 5 & 3 & 20 & 0.103 \\
Expert 4 & 5 & 3 & 3 & 4 & 2 & 17 & 0.087 \\
Expert 5 & 5 & 5 & 5 & 5 & 2 & 22 & 0.113 \\
Expert 6 & 5 & 4 & 4 & 4 & 3 & 20 & 0.103 \\
Expert 7 & 4 & 5 & 5 & 5 & 3 & 22 & 0.113 \\
Expert 8 & 5 & 4 & 4 & 4 & 3 & 20 & 0.103 \\
Expert 9 & 4 & 4 & 4 & 4 & 2 & 18 & 0.092 \\
Expert 10 & 3 & 5 & 5 & 4 & 2 & 19 & 0.097 \\
\hline
\end{tabular}

4.6. Risk Classification. In the final stage of risk event judgement, the risk grade evaluation method based on fuzzy mathematics optimization is used in this paper to obtain the
TABLE 10: The evaluation results of each expert.

\begin{tabular}{lcccccccccc}
\hline Expert & 1 & 2 & 3 & 4 & 5 & 6 & 7 & 8 & 9 & 10 \\
\hline Total risk value & 7.0 & 8.1 & 7.8 & 7.0 & 9.3 & 7.6 & 8.9 & 7.5 & 7.2 & 7.6
\end{tabular}

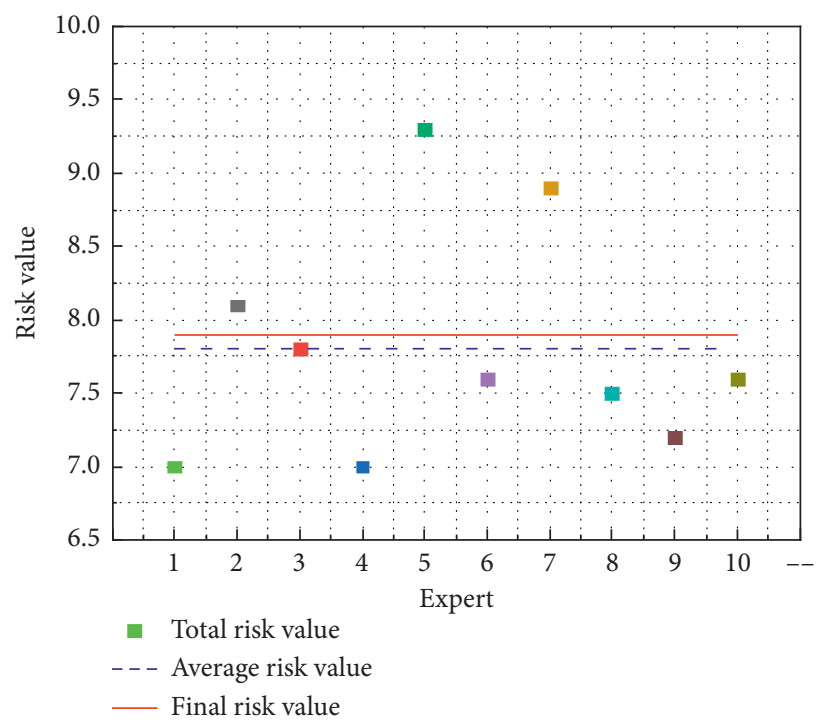

Figure 7: Total risk value of each expert.

degree of membership of the four risk grades divided by the total risk value: $\{(0.07 / 7.9),(0.25 / 7.9),(0.95 / 7.9),(0 / 7.9)\}$. According to the principle of the maximum degree of membership, the results show that the total risk value of the project is judged to be grade III, which is acceptable, but necessary measures are still needed to ensure construction safety.

In this paper, the optimized risk level evaluation method is that the four risk levels have their own membership functions, and each score has four risk levels of membership. The risk level of the score is judged by the size of the degree of membership. Meanwhile, the risk level evaluation method before optimization has obvious grade boundaries, and the risk level of the score can be judged by whether the score exceeds the boundary. For example, for 9.9 and 10 points, the evaluation result of the nonoptimized risk level evaluation method of 10 points belongs to grade II and that of 9.9 points belongs to grade III. The evaluation result of the optimized evaluation method is that the degrees of membership of 9.9 and 10 are $\{(0.16 / 9.9)$, $(0.64 / 9.9),(0.65 / 9.9),(0 / 9.9)\}$ and $\{(0.16 / 10),(0.66 / 10)$, $(0.63 / 10),(0 / 10)\}$, respectively. The risk value of 9.9 belongs to grade III, while the risk value of 10 belongs to grade II based on the degrees of membership. Although the evaluation results of the two evaluation methods are the same, the evaluation principle is completely different. The optimized evaluation method is more in line with people's understanding of the concept. For example, if age is the domain of discourse, then there is no clear boundary between "young," "middle-aged," and "old;" and if people's height is taken as the domain, there is no clear boundary for "tall," "mediumsized," and "short." These concepts are vague concepts, and 
the risk level is the same. That is to say, the degree to which elements in the domain of discourse conform to the concept is not an absolute 0 or 1 , but rather it is a real number from 0 to 1 . The optimized risk grade evaluation method in this paper embodies the central idea of fuzzy mathematics.

\section{Conclusion}

(1) The risk assessment method introduced in this paper is optimized from three aspects. First, the risk loss index is refined and divided into five indicators (casualties, economic losses, construction delays, environmental impacts, and social impacts) and different weights are given to the five indicators. Second, the expert weights are increased, and the evaluation index of expert weights is given. Third, fuzzy mathematics is used to form a new risk grade evaluation method by adding a membership function.

(2) The evaluation results of the case analysis in Chapter 4 show that, as shown in Figure 6, each risk event has a very different evaluation level for the five risk loss indicators. For example, for the first risk event, the economic losses are level 4, the casualties are level 3, the construction delays are level 2, the environmental impacts are level 3 , and the social impacts are level 3. It can be seen that a risk event must be evaluated from multiple aspects through a comprehensive analysis of the risk value, and the difference between giving the index weights and directly taking the average value is also obvious. The red line and blue line are obviously not coincident for the 31 risk events, but the results obtained after giving the index weights can more comprehensively reflect the risk loss of risk events. As shown in Figure 7, the score results of each expert are relatively large among the 10 experts. Seven experts scored no more than 8 points, 2 experts scored in the range of 8-9 points, and 1 expert scored more than 9 points. However, after increasing the weights of experts, the problem of there being a large difference in expert scoring results can be well solved. The risk rating evaluation method used in this paper has also been well applied in the case, which also reflects the fuzziness and inconsistency of the risk itself. It is certainly a good risk level evaluation method.

(3) In this paper, the optimization of the risk assessment method for DFP engineering is not limited to DFP engineering, and other engineering risk assessments can also be used for reference, including other industries, such as finance, nuclear power, etc.

\section{Data Availability}

The data sets used and analyzed during the current study are available from the corresponding author upon reasonable request.

\section{Conflicts of Interest}

The authors declare that they have no conflicts of interest.

\section{Acknowledgments}

The authors would like to show the gratitude to the financial supports from the National Natural Science Foundation of China (Nos. 51678164 and 51478118), the project supported by GDHVPS (2019), the Guangxi Science and Technology Plan Projects (AD18126011), the Guangxi Natural Science Foundation Program (2018GXNSFDA138009), the Scientific Research Foundation of Guangxi University (XTZ160590), and the Guangxi Special Experts Special Funds granted for Dr. Bo Wu.

\section{References}

[1] China Urban Rail Transit Association, 2017 Annual Statistical and Analysis Report for Urban Rail Transit, China Urban Rail Transit Association, 2018, in Chinese.

[2] F. Wang, L. Y. Ding, H. B. Luo, and P. E. D. Love, "Probabilistic risk assessment of tunneling-induced damage to existing properties," Expert Systems with Applications, vol. 41, no. 4, pp. 951-961, 2014.

[3] J. W. Seo and H. H. Choi, "Risk-based safety impact assessment methodology for underground construction projects in korea," Journal of Construction Engineering and Management, vol. 134, no. 1, pp. 72-81, 2008.

[4] Q. Z. Yu, L. Y. Ding, C. Zhou, and H. B. Luo, "Analysis of factors influencing safety management for metro construction in China," Accident Analysis \& Prevention, vol. 68, pp. 131-138, 2014.

[5] Q. Qian and P. Lin, "Safety risk management of underground engineering in China: progress, challenges and strategies," Journal of Rock Mechanics and Geotechnical Engineering, vol. 8, no. 4, pp. 423-442, 2016.

[6] Z. C. Chen, L. Yao, J. J. Yang et al., "A research review of project risk assessment methods," Applied Mechanics and Materials, vol. 496-500, pp. 2857-2862, 2014.

[7] W. Yan, L. Baoguo, and Q. Yi, "Fuzzy analytic network process and its application in tunnel engineering risk analysis," EJGE, vol. 20, pp. 6685-6701, 2015.

[8] J. He, H. Z. Pan, M. J. Chen et al., "Construction risk of foundation pit of subway station based on rough set theory and catastrophe progression method," Electronic Journal of Geotechnical Engineering, vol. 21, pp. 1615-1628, 2016.

[9] A. Valipour, N. Yahaya, N. Md Noor, J. Antuchevičienè, and J. Tamošaitiene, "Hybrid SWARA-COPRAS method for risk assessment in deep foundation excavation project: an Iranian case study," Journal of Civil Engineering and Management, vol. 23, no. 4, pp. 524-532, 2017.

[10] M. S. Islam, M. P. Nepal, and M. Skitmore, "Current research trends and application areas of fuzzy and hybrid methods to the risk assessment of construction projects," Advanced Engineering Informatics, vol. 33, pp. 112-131, 2017.

[11] L. Giannakos and Y. Xenidis, "Risk assessment in construction projects with the use of neural networks. Safety and reliability-safe societies in a changing world," in Proceedings of the 28th International European Safety and Reliability Conference, Trondheim, Norway, 2018. 
[12] J. Hegde and B. Rokseth, "Applications of machine learning methods for engineering risk assessment-a review," Safety Science, vol. 122, Article ID 104492, 2019.

[13] H. Zhi, "Risk management for overseas construction projects," International Journal of Project Management, vol. 13, no. 4, pp. 231-237, 1995.

[14] Y.-C. Kuo and S.-T. Lu, "Using fuzzy multiple criteria decision making approach to enhance risk assessment for metropolitan construction projects," International Journal of Project Management, vol. 31, no. 4, pp. 602-614, 2013.

[15] Ministry of Housing and Urban-Rural Development of the People's Republic of China, Risk Management Code for Underground Engineering Construction of Urban Rail Transit, Ministry of Housing and Urban-Rural Development of the People's Republic of China, Beijing, China, 2011, in Chinese.

[16] C. Samantra, S. Datta, S. S. Mahapatra et al., "Fuzzy based risk assessment module for metropolitan construction project: an empirical study," Engineering Applications of Artificial Intelligence, vol. 65, pp. 449-464, 2017.

[17] S. Li, Engineering Fuzzy Mathematics and Its Application, Harbin Institute of Technology Press, Harbin, China, 2004.

[18] W. K. B. Möller and M. Beer, "Fuzzy randomness. Uncertainty in civil engineering and computational mechanics," Computational Mechanics, vol. 36, no. 1, p. 83, 2005.

[19] Q. Zou, J. Zhou, C. Zhou, L. Song, and J. Guo, "Comprehensive flood risk assessment based on set pair analysisvariable fuzzy sets model and fuzzy AHP," Stochastic Environmental Research and Risk Assessment, vol. 27, no. 2, pp. 525-546, 2013.

[20] M. Cheng, Q. Wang, and H. Lin, "Risk assessment of the deep foundation pit based on the improved FMEA method," Journal of Civil Engineering and Management, vol. 35, no. 1, pp. 54-59, 2018.

[21] S. Zhang, "Construction risk evaluation of deep foundation pit based on G-FAHP," Journal of Civil Engineering and Management, vol. 33, no. 5, pp. 104-109, 2016, in Chinese.

[22] S. Liang, "Research on risk identification of metro station based on WBS-RBS method," Shanxi Architecture, vol. 42, no. 20, pp. 239-241, 2016, in Chinese.

[23] L. B. Wang and Y. Yi, "Risk identification and assessment of subway construction based on couplinng of WBS-rbs and fault tree analysis," Chinese Journal of Underground Space and Engineering, vol. 11, no. s2, pp. 772-779, 2015, in Chinese. 